\title{
ESTIMATIVA DA ÁGUA NO SOLO EM FLORESTA DE Eucalyptus grandis
}

\author{
VALDEMIR ANTONIO RODRIGUES ${ }^{1}$; PAULO TORRES FENNER ${ }^{1}$; CLÁUDIO ANGELI \\ SANSIGOLO $^{1}$ e MARIA HELENA MORAES ${ }^{1}$ \\ ${ }^{(1)}$ Faculdade de Ciências Agronômicas - FCA - UNESP - Botucatu - São Paulo - Brasil. \\ E-mails: valdemirrodrigues@fca.unesp.br - fenner@fca.unesp.br \\ sansigolo@fca.unesp.br - mhmoraes@fca.unesp.br
}

\section{RESUMO}

O trabalho teve por objetivo avaliar a umidade e densidade do solo, a quantidade de água armazenada no perfil e a porosidade média do solo com reflorestamento de Eucalyptus grandis, em comparação com o solo descoberto. As áreas de estudo estão localizadas no município de Lençóis Paulista, São Paulo, Brasil. As amostras foram coletadas nas camadas de $0 ; 20 ; 40 ; 60 ; 100$ e $300 \mathrm{~cm}$, nos meses de abril, junho, agosto e outubro de 2008. Os resultados evidenciam que a densidade é menor e a porosidade é maior no solo sob floresta de Eucalyptus quando comparado com o solo descoberto, em decorrência do maior teor de matéria orgânica na serrapilheira florestal. Além disso, o solo florestal apresenta menor quantidade de água armazenada no perfil do que o solo descoberto sem vegetação.

Palavras - chave: Eucalyptus, água, solo, armazenamento de água.

\section{RODRIGUES, V. A.; FENNER, P. T.; SANSIGOLO, C. A.; MORAES, M. H. SOIL WATER ESTIMATION IN Eucalyptus grandis FOREST}

\section{ABSTRACT}

The study aimed to assess the moisture and density of the soil, the amount of water stored in the profile, and the average soil's porosity with Eucalyptus grandis reforestation, compared to bare soil. The study areas are located in the Paulista region, in São Paulo, Brazil. The samples were collected in layers of $0,20,40,60,100$ and $300 \mathrm{~cm}$, in the months of April, June, August and October 2008. The results show that the density is lower and the porosity is higher in Eucalyptus forest soil compared to bare soil, due to the higher content of organic matter in forest leaf litter. Furthermore, the forest soil has a lower amount of water stored in profile than the bare soil without vegetation.

Keywords: Eucalyptus, water, soil, storage.

\section{INTRODUÇÃO}

A umidade das camadas do solo apresenta uma variabilidade importante nos domínios espacial e temporal, que pode levar a incerteza crítica para o manejo agrícola da água (HU et al., 2008). De acordo com Timm et al. (2006) a umidade influencia importantes processos no 
solo e na planta tais como: movimento de água, compactação do solo, aeração do solo e desenvolvimento radicular.

Lima (2010) relata que a infiltração da água no solo e a evapotranspiração representativa de diferentes tipos de vegetação desempenham papel fundamental na hidrologia da microbacia que sofreu alteração em sua cobertura. Os efeitos interativos entre a alteração da infiltração e da evapotranspiração decorrentes do manejo da cobertura florestal dependem da hidrologia do solo e de sua capacidade de armazenamento de água.

O estudo do comportamento da água no solo é muito complexo devido a heterogeneidade das características do solo como a densidade do solo, o tamanho, a forma e a disposição de vazios, a textura, a estrutura, a superfície específica, o teor de matéria orgânica, óxidos de ferro e outros fatores (JORGE, 1985). A intensidade de absorção de água pelo solo varia tanto no espaço como no tempo, o que é igualmente válido para o regime hidrológico de um solo e mesmo de grandes territórios, o autor ressalta ainda que a água de infiltração desloca-se diretamente por gravidade e ainda sob o efeito de outras forças, tais como: atrito, capilaridade, inércia, pressão do ar no solo; e o ar que se encontra preso nos poros do solo que diminui o coeficiente de infiltração.

A utilização inadequada do solo e da água tem proporcionado aumento de áreas degradadas e alterado a qualidade da água disponível em todas as regiões do mundo (RODRIGUES, 2011). A vegetação tem grande importância na manutenção das condições de porosidade do solo, tanto pelo desenvolvimento das raízes, quanto pela formação da matéria orgânica adicionada ao solo. $\mathrm{O}$ uso do solo no passado pode, em geral, modificar as características de infiltração inerentes do solo (LIMA, 1986).

Segundo Moura e Garcia (2000), a maioria das espécies de Eucalyptus desenvolveu mecanismos fisiológicos de adaptação às condições de déficit hídrico, com restrição ao consumo de água nos períodos secos do ano.

A grande importância dos reflorestamentos com espécies florestais do gênero Eucalyptus é sem dúvida, sua capacidade de adaptação e desenvolvimento em diferentes sítios, alta produtividade em torno de $50 \mathrm{~m}^{3} /$ hectare/ano, o que garante retorno financeiro pela venda da madeira.

As espécies do gênero eucalipto possuem rápido crescimento quando comparadas às espécies nativas, e isto faz com que a sua demanda por água seja maior, embora a eficiência no aproveitamento da mesma seja melhor. Assim como qualquer espécie vegetal, o eucalipto utiliza água para satisfazer suas demandas fisiológicas, promovendo assim o seu crescimento, segundo Oleriano e Dias (2007).

As plantações de Eucalyptus grandis exercem controle estomático eficiente em condições de baixa disponibilidade de água no solo e se comparam à Mata Atlântica quanto à evapotranspiração e ao uso da água (Almeida e Soares, 2003). O efeito da densidade populacional de plantas sobre o regime hídrico do solo pode ser atribuído, principalmente, às diferenças de quantidade de água transpirada, de interceptação de chuva pela copa e de interceptação de água pela manta orgânica depositada na superfície do solo. A redução da densidade populacional tende a aumentar o conteúdo de água no solo (LEITE et al., 1999).

Os reflorestamentos com Eucalyptus no Brasil abastecem o mercado consumidor de madeira, principalmente para a produção de papel e celulose, bem como o consumo de lenha e carvão vegetal. Com relação ao consumo de água do solo todos os vegetais consomem água de acordo com seus potenciais de desenvolvimento e condições hídricas.

Os Neossolos Quartzarênicos por serem muito arenosos, com baixa capacidade de agregação de partículas, condicionada pelos baixos teores de argila e de matéria orgânica, são muito suscetíveis à erosão e apresentam limitação quanto à capacidade de armazenamento de 
água disponível para as plantas. Consequentemente, requerem manejo adequado visando a economia de água e altas produtividades (SOUZA e LOBATO, 2005).

Rodrigues (1999), que realizou a quantificação da água no solo com cobertura de seringueira Hevea brasiliensis, verificou que as maiores variações de umidade do solo ocorreram próximas à superfície, até $0,20 \mathrm{~m}$ de profundidade e, os menores valores de umidade, foram encontrados nos meses de julho e agosto, coincidentes com os índices mais baixos de produção de látex.

O trabalho teve por objetivo avaliar a umidade e densidade do solo, a quantidade de água armazenada no perfil e a porosidade média do solo com reflorestamento de Eucalyptus grandis, em comparação com o solo descoberto sem vegetação.

\section{MATERIAL E MÉTODOS}

\subsection{Localização da Área}

A área de estudo está localizada na Fazenda Guanabara, uma das fazendas de reflorestamento da empresa Duratex, em Lençóis Paulista - SP, entre as coordenadas geográficas: $22^{\circ} 21^{\prime}(\mathrm{S})$ de latitude e $48^{\circ} 48^{\prime}$ (W) de longitude, com altitude de 560 metros. Segundo a classificação climática de Koeppen, o clima é tropical do tipo Aw, a temperatura média anual mínima é de $14,6^{\circ} \mathrm{C}$ e a máxima de $25,70^{\circ} \mathrm{C}$.

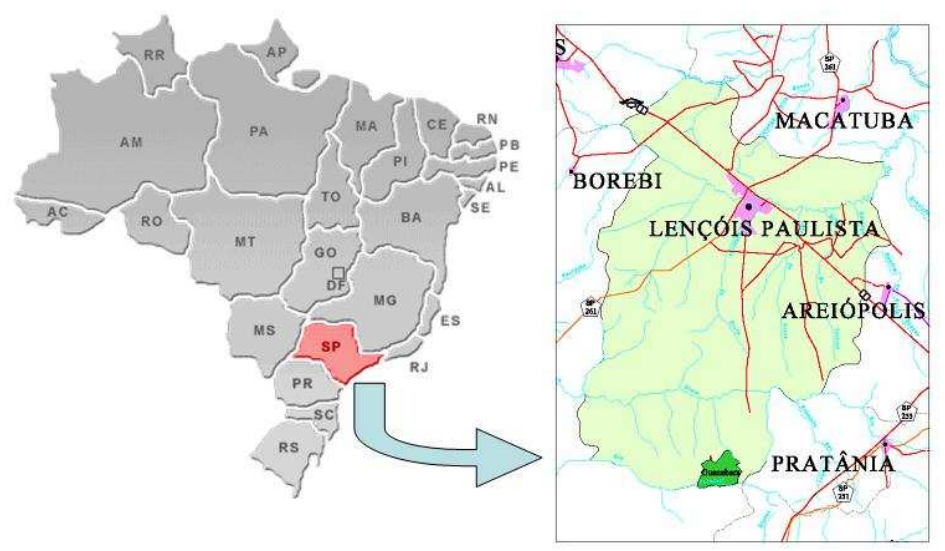

Figura 1. Localização geográfica da fazenda Guanabara em Lençóis Paulista - SP.

A quantificação da precipitação pluviométrica mensal em milímetros foi realizada de janeiro a dezembro de 2008, e a coleta com pluviômetro da estação meteorológica da Fazenda Guanabara da Duraflora no município de Lençóis Paulista - SP.

\subsection{Histórico da área de estudo}

O reflorestamento de Eucalyptus grandis com 6 anos de idade foi plantado em espaçamento de $3 \times 2$ metros, totalizando 1.666 indivíduos por hectare, área em que foram abertas as trincheiras sob dossel. A área sem cobertura vegetal foi selecionada próxima do Eucaliptal onde, após limpeza de ervas colonizadoras, foram abertas as trincheiras a céu aberto. 


\subsection{Solo}

O solo da área experimental é um Neossolo Quartzarênico que possui 846 g. $\mathrm{kg}^{-1} \mathrm{de}$ areia, 25 g. $\mathrm{kg}^{-1}$ de silte e 129 g. $\mathrm{kg}^{-1}$ de argila e ocorre em relevo suave ondulado.

\subsection{Análise física do solo}

Para a coleta de amostras indeformadas foram abertas trincheiras com $100 \mathrm{~cm}$ de profundidade. As amostras foram coletadas com anéis volumétricos de $100 \mathrm{~cm}^{3}$, no sentido vertical nas profundidades de: 0-10, 20-30, 40-50, 60-70 e 100-110 cm, com quatro repetições por camada, perfazendo 20 amostras ao longo do perfil, nos meses de abril e outubro de 2008, tanto para a área sob dossel de Eucalipto como a céu aberto. Com os dados médios foram estimadas as quantidades de água a 200 e $300 \mathrm{~cm}$ de profundidade.

Após a coleta de cada amostra foi realizada a limpeza externa dos anéis, para retirada do excesso de solo. Em seguida, os anéis foram envolvidos em filme plástico, para evitar a evaporação, e transportados para o laboratório.

A umidade do solo foi determinada considerando-se a massa do solo úmido obtida por pesagem das amostras logo após a coleta e a massa do solo seco determinada após a secagem, em estufa a $105^{\circ} \mathrm{C}$ até massa constante. A umidade do solo a base de volume foi calculada multiplicando-se a densidade do solo pela umidade a base seca do solo. As análises foram realizadas de acordo com EMBRAPA (1999).

A densidade do solo $\left(\mathrm{kg} \mathrm{dm}^{-3}\right)$ foi calculada pela relação entre a massa do solo seco $(\mathrm{g})$ e o volume total do solo $\left(\mathrm{cm}^{3}\right)$. A densidade das partículas do solo $\left(\mathrm{kg} \mathrm{dm}^{3}\right)$ foi obtida pela relação entre a massa do solo seco $(\mathrm{g})$ e o volume das partículas minerais e orgânicas $\left(\mathrm{cm}^{3}\right)$. A porosidade total do solo foi calculada utilizando os valores médios da densidade do solo $\left(\rho_{\mathrm{s}}\right)$ e da densidade das partículas do solo $\left(\rho_{\mathrm{p}}\right)$, pela equação: $\mathrm{Ps}=\left(1-\frac{\rho \mathrm{s}}{\rho_{\mathrm{P}}}\right) .100$, sendo: Ps $=$ porosidade do solo $(\%) ; \rho_{\mathrm{s}}=$ densidade do solo $\left(\mathrm{kg} \mathrm{dm}^{-3}\right) ; \rho_{\mathrm{p}}=$ densidade das partículas do solo $\left(\mathrm{kg} \mathrm{dm}^{-3}\right)$. A umidade do solo com base em volume $(\theta)$ foi determinada pelo produto do teor de umidade e a densidade do solo de acordo com KLAR (1988).

A quantificação do armazenamento de água no solo $(\Delta \mathrm{S})$ foi feita utilizando a umidade do solo a base de volume $(\theta)$ e a altura do perfil do solo $(\mathrm{cm})$, conforme equação: $\Delta \mathrm{S}=(\theta . h) .10 \mathrm{em}(\mathrm{mm})$ de acordo com Reichardt (1985).

\subsection{Análise estatística}

Os resultados foram analisados utilizando o programa SAS pela análise de variância e teste de comparação de médias Tukey no nível de $5 \%$ de significância e a dispersão dos resultados em relação à média foi expressa pelo desvio padrão.

\section{RESULTADOS E DISCUSSÃO}

O fornecimento de água para o solo nas áreas avaliadas ocorreu, exclusivamente, em função da precipitação. Na Figura 2 constam os valores de precipitação total a céu aberto (PA), ao longo do ano de 2008, nas áreas com reflorestamento de Eucalyptus grandis e com 
solo descoberto, na fazenda Guanabara, da empresa Duratex, em Lençóis Paulista - São Paulo - Brasil.

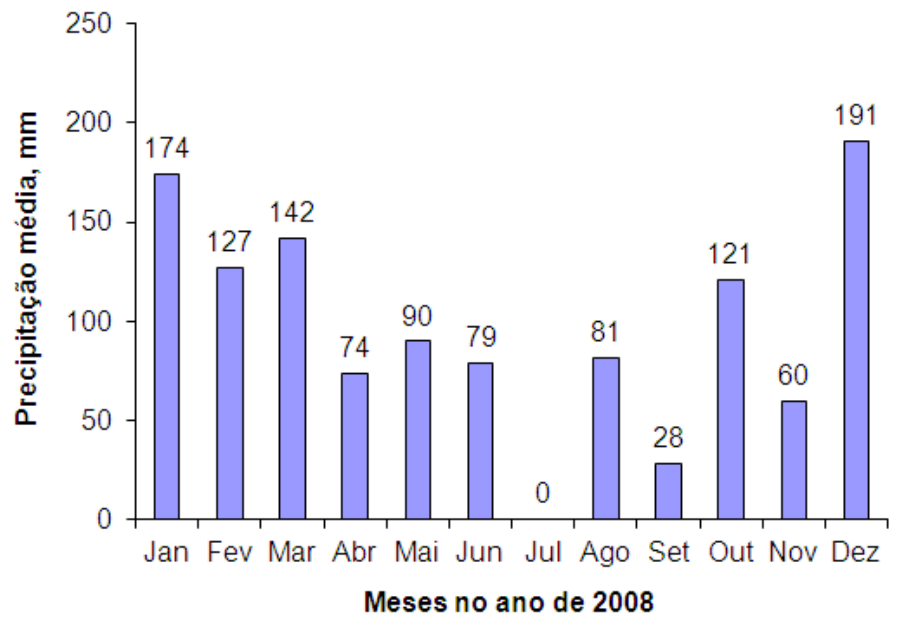

Figura 2. Precipitação média mensal a céu aberto no ano de 2008.

$\mathrm{O}$ mês de janeiro apresentou o maior número de eventos chuvosos (13 eventos). $\mathrm{Na}$ sequencia ocorreram 04 em fevereiro, 05 em março, 02 abril, 01 em maio, 02 em junho, zero em julho, 01 em agosto e setembro, 05 em outubro, 03 novembro e 04 em dezembro. A precipitação total foi de $1.166 \mathrm{~mm}$ para 41 chuvas ao longo do ano de 2008 .

Para o período de janeiro a abril foi observada uma precipitação de $517 \mathrm{~mm}$, enquanto que para o período de julho a outubro a precipitação foi bem menor, totalizando $230 \mathrm{~mm}$.

$\mathrm{Na}$ Tabela 1 estão apresentados os valores de armazenamento da água, em mm, no perfil do solo com $300 \mathrm{~cm}$ de profundidade, nas áreas com plantio de Eucalyptus grandis (A) e com solo descoberto (B), durante o ano.

Tabela 1. Água no perfil do solo (mm) com Floresta (A) e descoberto (B) em 2008

\begin{tabular}{ccccccccccccc}
\hline \multirow{2}{*}{$\begin{array}{c}\text { Perfil } \\
\text { (cm) }\end{array}$} & \multicolumn{3}{c}{ abril } & \multicolumn{2}{c}{ junho } & \multicolumn{2}{c}{ agosto } & \multicolumn{3}{c}{ Outubro } & \multicolumn{3}{c}{ DP* } & \multicolumn{3}{c}{ CV\%** } \\
\hline & A & B & A & B & A & B & A & B & A & B & A & B \\
\hline $0-4$ & 6,7 & 7,6 & 3,9 & 4,3 & 3,5 & 4,2 & 2,0 & 2,5 & 1,9 & 2,2 & 48,5 & 46,9 \\
$0-20$ & 31,9 & 41,4 & 12,6 & 20,6 & 27,2 & 22,8 & 10,3 & 17,8 & 10,7 & 10,7 & 52,0 & 41,7 \\
$0-40$ & 63,7 & 81,9 & 47,5 & 67,4 & 65,4 & 81,8 & 33,5 & 48,6 & 15,0 & 15,8 & 28,6 & 22,5 \\
$0-60$ & 97,9 & 124,4 & 71,9 & 99,4 & 89,3 & 128,1 & 61,1 & 93,2 & 16,7 & 17,6 & 20,8 & 15,8 \\
$0-100$ & 158,7 & 209,8 & 152,9 & 202,3 & 205,2 & 230,4 & 112,4 & 171,6 & 38,0 & 24,4 & 24,2 & 12,0 \\
$0-300$ & 476,1 & 629,4 & 312,6 & 447,6 & 410,9 & 508,8 & 368,0 & 478,2 & 70,6 & 79,6 & 17,9 & 15,4 \\
\hline
\end{tabular}

Solo com Eucalyptus (A); solo descoberto (B); *Desvio Padrão, ${ }^{* *}$ Coeficiente de variação

A água armazenada no solo com reflorestamento de Eucalyptus nas camadas superficiais entre $(0-4)$ e $(0-20) \mathrm{cm}$ apresentou maiores coeficientes de variação $(48,5 \%$ e $52,0 \%$, respectivamente), quando comparados com as mesmas camadas em solo descoberto (46,9\% e 41,7\%, respectivamente), com relação ao período de abril a outubro de 2008 , conforme (Tabela 1). Nestas camadas superficiais até $20 \mathrm{~cm}$ há uma maior dinâmica da água no solo, de acordo com Rodrigues (1999), que realizou a quantificação da água no solo com cobertura de seringueira e verificou que as maiores variações de umidade do solo ocorreram próximas à superfície, até $0,20 \mathrm{~m}$ de profundidade. 
O solo descoberto apresentou maior quantidade de água armazenada desde a superfície até os 3 metros de profundidade com 478,2 mm quando comparado com o solo sob floresta de Eucalyptus, com $368,0 \mathrm{~mm}$. Essa diminuição é resultado da transpiração, pois as raízes das árvores absorvem água e nutrientes do solo para o processo de evapotranspiração. A redução da densidade populacional tende a aumentar o conteúdo de água no solo (LEITE et al., 1999), como decorrência da menor taxa de transpiração. Observa-se, também, que a quantidade de água no solo aumenta ao longo da profundidade.

De acordo com González \& Alves (2005), em estudos com armazenamento de água e densidade do solo sob três condições de superfície, em um Cambissol gleico de Lugo, Espanha, a variação no conteúdo de água $\left(0,15 \mathrm{~m}^{3} \mathrm{~m}^{-3}\right)$ foi menor para o solo descoberto, fato explicado pela evaporação mais lenta devido à não existência de plantas e, possivelmente, à formação de uma crosta superficial, contrastando com $0,31 \mathrm{~m}^{3} \mathrm{~m}^{-3}$, observado nas áreas com pastagem.

De maneira geral, a crosta não permite conexão entre os poros da superfície do solo e o interior do perfil, de modo que o transporte de água e ar se encontra limitado, visto que poros de transmissão são obstruídos pela reorganização das partículas superficiais, pelo colapso da estrutura pelos diversos mecanismos de desagregação (Fiès e Panini, 1995 \& Taboada e Castro, 2001 apud GONZÁLEZ e ALVES 2005).

Os resultados das variáveis fisico-hídricas do solo com Eucalyptus e solo descoberto, quais sejam, umidade com base em peso (Ubp), densidade do solo $(\rho)$, umidade com base em volume $(\theta)$ e, armazenamento de água no solo $(\Delta \mathrm{S})$ em $(\mathrm{mm})$ no perfil do solo em função das diferentes profundidades do perfil e das duas épocas do ano hídrico, nos períodos chuvoso e seco constam das Tabelas 2 e 3 .

Tabela 2. Análise físico-hídrica do solo com Eucalyptus (A) e descoberto (B), no período chuvoso, em abril de 2008

\begin{tabular}{ccccccccccc}
\hline $\begin{array}{c}\text { Camada } \\
(\mathrm{cm})\end{array}$ & \multicolumn{2}{c}{$\begin{array}{c}\mathrm{Ubp} \\
(\mathrm{g} / 100 \mathrm{~g})\end{array}$} & \multicolumn{2}{c}{$\begin{array}{c}\rho \\
\left(\mathrm{g} / \mathrm{cm}^{3}\right)\end{array}$} & \multicolumn{2}{c}{$\begin{array}{c}\Theta \\
\left(\mathrm{cm}^{3} / \mathrm{cm}^{3}\right)\end{array}$} & \multicolumn{2}{c}{$\begin{array}{c}\Delta \text { s faixa } \\
(\mathrm{mm})\end{array}$} & \multicolumn{2}{c}{\begin{tabular}{c}
\multicolumn{2}{c}{ Perfil } \\
$(\mathrm{mm})$
\end{tabular}} \\
\cline { 2 - 12 } & $\mathrm{A}$ & $\mathrm{B}$ & $\mathrm{A}$ & $\mathrm{B}$ & $\mathrm{A}$ & $\mathrm{B}$ & $\mathrm{A}$ & $\mathrm{B}$ & $\mathrm{A}$ & $\mathrm{B}$ \\
\hline 0 & 0,111 & 0,118 & 1,50 & 1,62 & 0,166 & 0,191 & 6,7 & 7,6 & 6,7 & 7,6 \\
20 & 0,100 & 0,129 & 1,60 & 1,61 & 0,160 & 0,207 & 6,4 & 8,3 & 31,9 & 41,4 \\
40 & 0,100 & 0,127 & 1,60 & 1,61 & 0,159 & 0,205 & 6,4 & 8,2 & 63,7 & 81,9 \\
60 & 0,102 & 0,130 & 1,60 & 1,60 & 0,163 & 0,207 & 6,5 & 8,3 & 97,9 & 124,4 \\
100 & 0,113 & 0,131 & 1,40 & 1,60 & 0,159 & 0,210 & 6,4 & 8,4 & 158,7 & 209,8 \\
Média & 0,105 & 0,127 & 1,54 & 1,61 & 0,161 & 0,204 & 6,5 & 8,2 & & \\
\hline
\end{tabular}

Solo com Eucalyptus (A); solo descoberto (B)

O teor de água observado para as áreas avaliadas é considerado baixo e está de acordo com a classe de textura arenosa do solo que, consequentemente, apresenta limitação quanto a capacidade de armazenamento de água (SOUZA e LOBATO, 2005). 
Tabela 3. Análise físico-hídrica do solo com Eucalyptus (A) e descoberto (B), no final do período seco, em outubro de 2008

\begin{tabular}{|c|c|c|c|c|c|c|c|c|c|c|}
\hline \multirow[t]{2}{*}{$\begin{array}{c}\text { Camada } \\
(\mathrm{cm})\end{array}$} & \multicolumn{2}{|c|}{$\begin{array}{c}\text { Ubp } \\
(\mathrm{g} / 100 \mathrm{~g})\end{array}$} & \multicolumn{2}{|c|}{$\begin{array}{c}\rho \\
\left(\mathrm{g} / \mathrm{cm}^{3}\right)\end{array}$} & \multicolumn{2}{|c|}{$\begin{array}{c}\theta \\
\left(\mathrm{cm}^{3} / \mathrm{cm}^{3}\right)\end{array}$} & \multicolumn{2}{|c|}{$\begin{array}{c}\Delta \text { s faixa } \\
(\mathrm{mm})\end{array}$} & \multicolumn{2}{|c|}{$\begin{array}{c}\Delta \text { s Perfil } \\
(\mathrm{mm})\end{array}$} \\
\hline & $\mathrm{A}$ & B & $\mathrm{A}$ & $\mathrm{B}$ & A & B & A & $\mathrm{B}$ & A & $\mathrm{B}$ \\
\hline 0 & 0,033 & 0,040 & 1,51 & 1,53 & 0,050 & 0,062 & 2,0 & 2,5 & 2,0 & 2,5 \\
\hline 20 & 0,033 & 0,057 & 1,57 & 1,57 & 0,052 & 0,089 & 2,1 & 3,6 & 10,3 & 17,8 \\
\hline 40 & 0,041 & 0,069 & 1,61 & 1,61 & 0,066 & 0,110 & 2,6 & 4,4 & 33,5 & 48,6 \\
\hline 60 & 0,046 & 0,069 & 1,61 & 1,60 & 0,074 & 0,111 & 3,0 & 4,4 & 61,1 & 93,2 \\
\hline 100 & 0,057 & 0,077 & 1,61 & 1,60 & 0,094 & 0,123 & 3,8 & 4,9 & 112,4 & 171,6 \\
\hline Média & 0,042 & 0,062 & 1,58 & 1,58 & 0,067 & 0,099 & 2,7 & 4,0 & & \\
\hline
\end{tabular}

Solo com Eucalyptus (A); solo descoberto (B)

Quando se compara o solo com floresta com o solo descoberto no período chuvoso (Tabela 2) observa-se para a condição de floresta que a densidade do solo média foi de 1,54 $\mathrm{g}$ $\mathrm{cm}^{-3}$, enquanto que para o solo descoberto foi de $1,61 \mathrm{~g} \mathrm{~cm}^{-3}$. $\mathrm{O}$ teor de água a base de volume foi de 0,161 e $0,204 \mathrm{~cm}^{3}$ de água $\mathrm{cm}^{-3}$ de solo e, o armazenamento de água no solo foi de 158,7 e $209,8 \mathrm{~mm}$, respectivamente.

O solo sob vegetação de eucalipto apresentou menor teor de água que o solo descoberto, tanto no período chuvoso como no seco. Em média os valores foram de 0,105 e $0,042 \mathrm{~cm}^{3} \mathrm{~cm}^{-3}$ para o solo sob eucalipto e de 0,127 e $0,062 \mathrm{~cm}^{3} \mathrm{~cm}^{-3}$ para o solo descoberto, respectivamente nos meses de abril e outubro. Esses valores representam uma retenção de água pelo solo $60 \%$ menor para as áreas com eucalipto e $51,2 \%$ menor para as áreas com solo descoberto, em função da menor precipitação verificada nos meses que antecederam a avaliação do mês de outubro. A retenção de água pelo solo foi, em média, 20,95 \% e 47,62 \% maior para o solo descoberto, respectivamente para os meses de abril e outubro, o que pode ter atribuído à maior evapotranspiração que ocorre nas áreas com as plantas de eucalipto, conforme comentam Oleriano e Dias (2007) e Lima (2010).

Quando se compara o solo com floresta e solo descoberto no período seco (Tabela 3) observa-se para a condição de floresta e de solo descoberto que a densidade do solo média de $1,58 \mathrm{~g} \mathrm{~cm}^{-3}$. O teor de água a base de volume no solo foi de: 0,067 e $0,099 \mathrm{~cm}^{3}$ água cm $\mathrm{cm}^{-3}$ solo e, o armazenamento de água no solo de $112,4 \mathrm{~mm}$ e $171,6 \mathrm{~mm}$, respectivamente.

Os resultados do armazenamento de água no perfil do solo em função das diferentes profundidades e épocas do ano hídrico podem ser visualizados na Figura 3. 


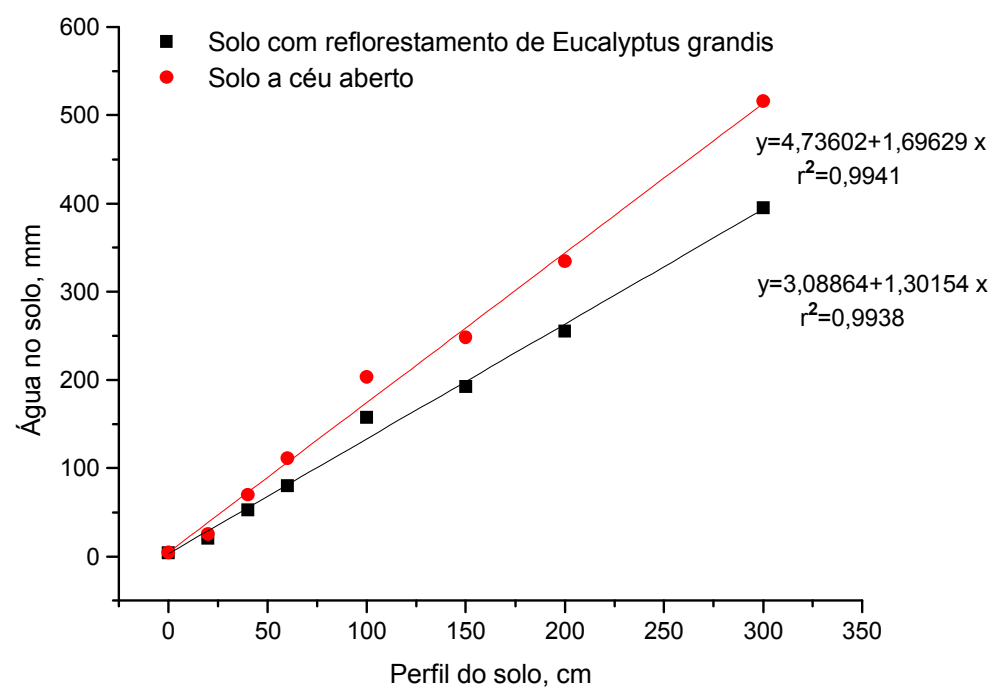

Figura 3. Armazenamento de água no solo com Eucalyptus grandis e solo descoberto.

O armazenamento de água no solo nestas condições estudadas, em mm, pode ser estimado pelas seguintes equações: água no solo em ambientes com vegetação de Eucalyptus grandis, por $\mathrm{y}=3,08864+1,30154 \mathrm{x}\left(\mathrm{r}^{2}=0,9938\right)$ e em solo sem vegetação a céu aberto por y $=4,73602+1,69629 \mathrm{x}\left(\mathrm{r}^{2}=0,9941\right)$. A variável dependente (y) é a água no solo, em $\mathrm{mm}$, e a variável independente (x) é o perfil do solo, em cm. Nota-se, claramente, que o solo com cobertura vegetal de Eucalyptus grandis apresentou um menor quantitativo de água, devido ao processo de transpiração, movimentação da água, solo, planta, atmosfera, quando comparado ao solo em ambiente sem vegetação a céu aberto.

A Tabela 4 mostra o resumo da análise de variância tipo fatorial considerando os fatores Solo - S (sem cobertura e com cobertura vegetal), Profundidade do perfil do solo - $\mathrm{P}$ $(0,100$ e $300 \mathrm{~cm})$ e Meses - M (abril, junho, agosto e outubro) e interações entre eles, com quatro repetições, para quantidade de água armazenada no solo.

Tabela 4. Análise de variância fatorial para os meses, tipo e profundidade do solo

\begin{tabular}{cccc}
\hline FV & GL & QM & F \\
\hline S & 1 & 85738,5 & $49,949^{*}$ \\
P & 2 & 1646107,3 & $958,982^{*}$ \\
M & 3 & 18,1 & $0,011^{\text {ns }}$ \\
SxP & 2 & 35855,7 & $20,889^{*}$ \\
SxM & 3 & 11,4 & $0,007^{\text {ns }}$ \\
PxM & 6 & 11,4 & $0,007^{\text {ns }}$ \\
SxPxM & 6 & 13,1 & $0,008^{\text {ns }}$ \\
\hline
\end{tabular}

(*) significativo a 5\%; (ns) não significativo, (S) tipo de solo, (P) profundidade do solo, $(\mathrm{M})$ meses.

A análise de variância mostra efeito significativo do tipo de cobertura do solo (S), da profundidade do perfil do solo $(\mathrm{P})$ e interação entre eles $(\mathrm{SxP})$ para quantidade de água no solo. A interação significativa indica que o comportamento da cobertura vegetal do solo depende do nível de profundidade do perfil do solo considerado. 
Nas profundidades (100 e $300 \mathrm{~cm}$ ) as diferenças foram significativas, e quanto maior a profundidade $(300 \mathrm{~cm})$ maior diferença atribuída ao tipo de cobertura do solo (S). Este comportamento diferenciado do tipo de cobertura do solo nas diferentes profundidades do perfil do solo foi detectado como interação significativa SxP na análise de variância geral.

A diferença entre meses no teor de água no solo pode ser observada quando da comparação de meses dentro do tipo de cobertura do solo e profundidade do perfil do solo, ou seja, M(S,P). Observa-se que na camada superficial do solo (profundidade 0 a $4 \mathrm{~cm}$ ) há uma diferença considerável e significativa para teor de água no solo quando da comparação dos meses de abril e outubro, tanto para o solo sem cobertura quanto para o solo com cobertura. Como visto, anteriormente, esta camada superficial do solo apresentou alta variação em função dos meses (Tabela 1). As maiores profundidades do perfil do solo $(100$ e $300 \mathrm{~cm})$ apresentaram menores diferenças, embora significativas, para teor de água no solo em função dos meses. Nestas camadas nota-se uma maior homogeneidade dos teores de água no solo em função dos meses.

A densidade do solo na camada superficial sob floresta de Eucalipto foi de 1,51 e, em valores médios no perfil, de $1,56 \mathrm{~g} \mathrm{~cm}^{-3}$. Já a densidade das partículas do solo foi de 2,61 $\mathrm{g}$ $\mathrm{cm}^{-3}$, resultando numa porosidade na superfície de $42,15 \%$ e no perfil de $40,23 \%$, o que pode ser atribuído a maior quantidade de matéria orgânica oriunda da serrapilheira das plantas de Eucalipto.

A densidade do solo na superfície do solo descoberto foi igual a $1,62 \mathrm{~g} \mathrm{~cm}^{-3}$ e, a densidade das partículas de 2,61 $\mathrm{g} \mathrm{cm}^{-3}$, resultando numa menor porosidade do solo de $37,93 \%$. e, no perfil, de 38,78\%. Por esses resultados pode-se observar que o solo desprotegido apresenta uma menor porosidade quando comparado com o solo sob floresta de Eucalipto.

\section{CONCLUSÕES}

1. A menor densidade e a maior porosidade do solo sob floresta em comparação com o solo descoberto são decorrentes do maior teor de matéria orgânica de serrapilheira florestal.

2. O ambiente com cobertura florestal de Eucalyptus apresenta menor quantidade de água armazenada no solo, ao longo do perfil, quando comparado com o ambiente descoberto.

\section{REFERÊNCIAS BIBLIOGRÁFICAS}

ALMEIDA, A. C., SOARES, J. V. Comparação entre uso de água em plantações de Eucalyptus grandis e floresta ombrófila densa (mata atlântica) na costa leste do Brasil. R. Árvore, Viçosa-Mg, v.27, n.2, p.159-170, 2003.

EMPRESA BRASILEIRA DE PESQUISA AGROPECUÁRIA (EMBRAPA). Centro Nacional de Pesquisa de Solos. Sistema brasileiro de classificação de solos. Rio de Janeiro, 1999. 412p.

GONZÁLEZ, A. P.; ALVES, M. C. Armazenamento de água e densidade do solo sob três condições de superfície, em um Cambissol gleico de Lugo, Espanha. Revista Brasileira de 
Engenharia Agrícola e Ambiental, v.9, n.1, p.45-50, 2005. Campina Grande, PB, DEAg/UFCG.

HU, W.; SHAO, M. A.; WANG, Q. J.; e REICHARDT, K.. Soil water content temporalspatial variability of the surface layer of a Loess Plateau hillside in China. Sci. Agric., vol. 65, n. 3, p. 277-289, 2008.

JORGE, J. A. Física e manejo dos solos tropicais. Instituto Campineiro de Ensino Agrícola. Campinas. 1985. 328p.

KLAR, A. E. A água no sistema solo-planta-atmosfera. Nobel, 2ª Edição, São Paulo, 1988, $408 \mathrm{p}$.

LEITE, F. P.; BARROS, N.F.; NOVAIS, R.F.; SANS, L.M.A.; FABRES, A.S. Relações hídricas em povoamento de Eucalipto com diferentes densidades populacionais. R. Bras. Ciência do Solo, 23: p.9-16, 1999.

LIMA, W. P. Princípios de hidrologia florestal para o manejo de bacias hidrográficas. ESALQ, Piracicaba, 1986, 241p.

LIMA, W. P. A silvicultura e a água: ciência, dógmas, desafios. Instituto BioAtlântica, Rio de Janeiro. Cadernos do Diálogo. v1, 2010, 64p.

MOURA, A. L.; GARCIA, C. H. A cultura do eucalipto no Brasil. SBS, Sociedade Brasileira de Silvicultura. São Paulo. 2000, 112p.

OLERIANO, E. dos S.; DIAS, H. C. T. A dinâmica da água em microbacias hidrográficas reflorestadas com eucalipto. Anais I Seminário de Recursos Hídricos da Bacia Hidrográfica do Paraíba do Sul: o Eucalipto e o Ciclo Hidrológico, Taubaté, Brasil, 07-09 novembro 2007, IPABHi, p. 215-222.

REICHARDT, K. Processos de Transferência no Sistema Solo-Planta-Atmosfera. Fundação Cargill, $4^{\text {a }}$ Edição, 1985. 466p.

RODRIGUES, V. A. Manejo da seringueira Hevea brasiliensis Muell. Arg. e seus efeitos na produção de látex e na conservação da microbacia do córrego da Barra Grande. Tese (Doutorado em Geociências e Meio Ambiente). Rio Claro, IGCE, UNESP, 1999, 113p.

RODRIGUES, V. A. Análise dos processos hidrológicos em modelo didático de microbacias. Revista Científica Eletrônica de Engenharia Florestal. Garça. R. C. E. E. F., v.17, n.1, fev, 2011.

SOUZA, D.M.G.; LOBATO, E. Agência de informação EMBRAPA. Bioma Cerrado. Areia Quartzosa / Neossolo Quartzarênico. 2005. Disponível em: http://www.agencia.cnptia.embrapa.br/Agencia16/AG01/arvore/AG01_2_10112005101955.ht ml. Acesso em: 23/10/2012.

TIMM, L. C.; PIRES, L.F.; ROVERATTI, R.; ARTHUR, R.C.J.; REICHARDT, K.; 
OLIVEIRA, J.C.M.; BACCHI, O.O.S. Field spatial and temporal patterns of soil water content and bulk density changes. Sci. agric., vol. 63, n. 1, p. 55-64, 2006. 